Article

\title{
Functional Analysis of Odorant-Binding Proteins 12 and 17 from Wheat Blossom Midge Sitodiplosis mosellana Géhin (Diptera: Cecidomyiidae)
}

\author{
Weining Cheng ${ }^{1, *}$, Yudong Zhang ${ }^{1}$, Jinlin Yu ${ }^{1}$, Wei Liu ${ }^{1}$ and Keyan Zhu-Salzman ${ }^{2, *}$ \\ 1 Key Laboratory of Plant Protection Resources \& Pest Management of the Ministry of Education, \\ College of Plant Protection, Northwest A\&F University, Yangling 712100, China; zydskrr@gmail.com (Y.Z.); \\ yujinlin91@nwafu.edu.cn (J.Y.); cherryapple788@gmail.com (W.L.) \\ 2 Department of Entomology, Texas A\&M University, College Station, TX 77843, USA \\ * Correspondence: chengwn@nwsuaf.edu.cn (W.C.); ksalzman@tamu.edu (K.Z.-S.)
}

Received: 19 November 2020; Accepted: 15 December 2020; Published: 17 December 2020

check for updates

Simple Summary: Sitodiplosis mosellana is one of the most destructive pests of wheat. Adults rely highly on wheat spike volatiles to search and locate oviposition sites. Insect odorant-binding proteins (OBPs) are important in binding and transporting host plant volatiles to the olfactory receptors. Therefore, OBP-based behavioral interference is believed to be a novel and effective pest management strategy. The objectives of this study were to clone two $S$. mosellana female antenna-enriched OBP genes (SmosOBP12 and SmosOBP17), determine the functions of the encoded SmosOBP proteins in binding wheat volatiles, and investigate behavioral responses of female $S$. mosellana to odorant molecules. Results indicated that SmosOBP12 had a broader ligand-binding spectrum than SmosOBP17 to wheat volatiles. Female $S$. mosellana showed intensive response to 3-hexanol, 1-octen-3-ol, D-panthenol, 3-carene, (Z)-3-hexenylacetate, hexyl acetate, methyl salicylate, heptyl acetate, ethyl heptanoate, $\alpha$-farnesene, and ocimene. Notably, all these compounds except $\alpha$-farnesene exhibited strong affinity to SmosOBP12. In conclusion, SmosOBP12 may play more crucial roles than SmosOBP17 in perception and transportation of biologically active host volatiles. This information has enhanced our molecular understanding of the $S$. mosellana olfaction, which could also serve as an important reference for developing attractants or repellents to control this pest.

\begin{abstract}
The wheat blossom midge Sitodiplosis mosellana, one of the most disastrous wheat pests, depends highly on olfactory cues to track suitable plants. To better understand the olfactory recognition mechanisms involved in host selection, in the present study we cloned two S. mosellana adult antenna-specific odorant binding protein (OBP) genes, SmosOBP12 and SmosOBP17, and evaluated bacterially expressed recombinant proteins for their selectivity and sensitivity for host wheat volatiles using the fluorescence-based ligand binding assay. The results showed that both SmosOBPs effectively bound alcohol, ester, ketone, and terpenoid compounds. Particularly, SmosOBP12 had significantly higher affinities $\left(\mathrm{K}_{\mathrm{i}}<10.5 \mu \mathrm{M}\right)$ than SmosOBP17 $\left(\mathrm{K}_{\mathrm{i}} 2>0.1 \mu \mathrm{M}\right)$ to 3-hexanol, 1-octen-3-ol, D-panthenol, 3-carene, (Z)-3-hexenylacetate, hexyl acetate, methyl salicylate, heptyl acetate, and ethyl heptanoate. Consistently, S. mosellana females were attracted to all these chemicals in a behavioral assay using Y-tube olfactometer. SmosOBP12 also bound aldehyde, but neither bound alkanes. Notably, SmosOBP12 exhibited strong affinity to ocimene $\left(\mathrm{K}_{\mathrm{i}}=8.2 \mu \mathrm{M}\right)$ that repelled S. mosellana. SmosOBP17, however, was insensitive to this compound. Taken together, our results indicate that SmosOBP12 may play a greater role than SmosOBP17 in perceiving these biologically active plant volatiles.
\end{abstract}

Keywords: Sitodiplosis mosellana; odorant-binding protein; wheat volatiles; fluorescence binding assay; behavioral assay 


\section{Introduction}

Important insect behaviors such as host plant selection, mate finding, and oviposition site searching are mediated by volatile chemical signals released from plants and conspecific partners [1-4]. Insects rely on their highly sensitive and specific olfactory systems to detect and discriminate these semiochemicals [5-7]. As the initial step of odorant reception, small water-soluble carrier proteins, namely the odorant-binding proteins (OBPs), selectively bind and transport external odorant molecules through the aqueous sensillar lymph to specific odorant receptors (ORs) on the dendrite membrane of olfactory neurons, activating the signal transduction pathway $[8,9]$. OBPs thus could be potential targets in the effort of interrupting chemical communications within species, and between insect pests and their host plants. Such an indirect insecticidal approach could play a crucial role in integrated pest management, broadening the arsenal of available tools for pest monitoring and control [10-12].

The first insect OBP was identified in the antennae of male Antheraea polyphemus using a radiolabeled pheromone [13]. With the development of molecular and high-throughput sequencing techniques, a large number of OBPs have been identified from insects belonging to at least eight different orders [14-20]. They all possess six conserved cysteine residues which form three disulfide bridges. These OBPs are generally classified into two subfamilies, namely general OBPs (GOBPs) and pheromone-binding proteins (PBPs) based on amino acid sequence homology and ligand specificity [21]. It is suggested that PBPs are male antenna-specific and respond mainly to pheromone components [22-25], whereas GOBPs are mainly expressed in antennae of both sexes and interacted with host plant volatiles [26-28]. Multiple OBPs with distinct functions can generally be found within a single insect species [29-31]. For instance, GmolOBP10 of the oriental fruit moth Grapholita molesta has very strong affinities to hexanol and dodecanol while GmolOBP4 does not bind to these two compounds at all. Instead, the best ligands for GmolOBP4 are hexanal and pear ester [32]. MmedOBP2 from parasitic wasp Microplitis mediator mainly binds aromatics, but MmedOBP6 primarily interacts with terpenoids, and MmedOBP5 only binds $\beta$-ionone [33].

The wheat blossom midge Sitodiplosis mosellana Gehin (Diptera: Cecidomyiidae) is one of the most damaging pests of wheat, causing serious yield loss in some parts of the Northern hemisphere [34,35]. This midge oviposits on wheat spikes primarily before anthesis, but exhibits apparently different preference among wheat varieties [36,37]. Studies have showed that volatiles emitted from wheat spikes are crucial in midge oviposition site selection [38]. Antennae of the midge possess numerous sensillar hairs or pegs, where odorant reception occurs [39]. Currently, monitoring of adult S. mosellana populations mainly depends on net sweeping and sex pheromone traps [40,41]. However, net sweeping is time-consuming. Moreover, adults are small in size ( $3 \mathrm{~mm}$ in body length) and most active right after dusk, making their identification and quantification hard. Using a pheromone trap may not detect outbreaks in a timely manner because the pheromone (i.e., 2, 7-nonanediyl dibutyrate) affects only males, however, females are better fliers and greater in number than the males [42,43]. More importantly, the female midge is directly responsible for infestation by oviposition [36]. Therefore, development of new strategies based on olfactory cues from host plants could represent a significant improvement of current monitoring of $S$. mosellana.

We have previously characterized three of the 26 candidate OBPs currently annotated in S. mosellana [44]. We demonstrate that these three OBPs, SmosOBPs 11, 16, and 21, differ in their affinity to wheat volatiles [45]. To further explore OBP functionality in this midge, here we cloned another two OBP genes highly expressed in female antennae (i.e., SmosOBP12 and SmosOBP17), and evaluated their selectivity and sensitivity to different host volatile components using a fluorescence competitive binding assay [46]. We also examined behavioral responses of adult S. mosellana to odorant molecules. Results have shed more light on the mechanism of host searching in S. mosellana. 


\section{Materials and Methods}

\subsection{Experimental Insects}

S. mosellana cultures were established by taking soil samples from a wheat field with severe S. mosellana damage at Zhouzhi, Shaanxi Province, China, during February 2017, and the soil samples with insects were stored at $4{ }^{\circ} \mathrm{C}$. When needed, samples were transferred to pots $(12 \mathrm{~cm}$ in diameter) and incubated at $24{ }^{\circ} \mathrm{C}$ with $70 \%$ relative humidity (R.H.). Pots were periodically watered to maintain moisture for insect development [47]. Adults generally emerged within 3 weeks under these conditions. Females were used for antenna collection and behavioral assays, considering the fact that in the field, females are more abundant and possess stronger flight capacity, and are responsible for infestation due to their oviposition [42,43]. It should be noted that females used in the experiments may have mated since they came from containers with mixed sex.

\subsection{RNA Isolation, cDNA Synthesis, and OBP Cloning}

Female antennae (about 300) were carefully removed, immediately frozen in liquid nitrogen, and stored at $-80^{\circ} \mathrm{C}$ until use. Total RNA from dissected antennae was extracted with the RNAsimple Total RNA Kit (Tiangen, Beijing, China) according to the user's manual. The integrity of total RNA was examined with $1 \%$ agarose gel electrophoresis, and the purity was determined by a spectrophotometer, i.e., the $\mathrm{OD}_{260} / \mathrm{OD}_{280}$ value. cDNAs were synthesized from $1.0 \mu \mathrm{g}$ total RNA using PrimeScript ${ }^{\mathrm{TM}}$ II 1 st Strand cDNA Synthesis kit (TaKaRa, Dalian, China) following the manufacturer's instructions.

We selected SmosOBP12 and SmosOBP17 as target genes because of their specific expression and/or high abundance in S. mosellana female antennae [44]. Partial sequences of two candidate SmosOBPs were identified based on the previously annotated transcriptome of $S$. mosellana. Of these, the $3^{\prime}$ sequence was intact for SmosOBP17 but missing for SmosOBP12. To obtain the complete open reading frames (ORF), gene-specific primers for 3'-RACE for SmosOBP12 and 5'-RACE for both genes (Table 1) were synthesized based upon the identified unigene sequences. $5^{\prime}$-and $3^{\prime}$-RACE were performed with the $5^{\prime}$-Full RACE Kit with TAP and the $3^{\prime}$-Full RACE Core Set with PrimeScript ${ }^{\text {TM }}$ RTase (TaKaRa, Dalian, China) in accordance with the recommended protocols. The primary and nested PCR conditions were as follows: initial denaturation for $3 \mathrm{~min}$ at $94{ }^{\circ} \mathrm{C} ; 20$ cycles of $30 \mathrm{~s}$ at $94{ }^{\circ} \mathrm{C}, 30 \mathrm{~s}$ at $55^{\circ} \mathrm{C}$, and $60 \mathrm{~s}$ at $72{ }^{\circ} \mathrm{C}$; a final extension of $10 \mathrm{~min}$ at $72{ }^{\circ} \mathrm{C}$. The PCR products were purified using the DNA Purification kit (Tiangen, Beijing, China), ligated into the vector pMD-19T (TaKaRa, Dalian, China), and then transformed into Escherichia coli (E. coli) DH5 $\alpha$ competent cells (Tiangen, Beijing, China), respectively. Three or more colonies were randomly selected for plasmid DNA extraction and sequencing (Invitrogen Biotechnology Co., Ltd., Shanghai, China).

Table 1. Primers used in cloning and expression of Sitodiplosis mosellana odorant-binding proteins 12 and 17 (SmosOBP12 and SmosOBP17).

\begin{tabular}{|c|c|c|}
\hline Primer Name & Sequence $\left(5^{\prime}-3^{\prime}\right)$ & Purpose \\
\hline OBP12-outer & TACTCGTAAGCACTTCTTGCC & \multirow{4}{*}{$5^{\prime} \mathrm{RACE}$} \\
\hline OBP12-inner & CACTTCTTGCCCATGCGA & \\
\hline OBP17-outer & GAAGAGCTAACGCAAATGATGAC & \\
\hline OBP17-inner & CCGGAGCTTCTGATGATCTTATT & \\
\hline OBP12-outer & GTCACCGACGAGGCGAT & \multirow{3}{*}{$3^{\prime} \mathrm{RACE}$} \\
\hline OBP12-inner & AGGCGATCCGAGAATTTAGTG & \\
\hline OBP12-forward & TCATCAAGCCCAACTTCTGT & \\
\hline OBP12-reverse & TTAAAGCAAGAAGTAATGTTTTGG & \multirow{2}{*}{ ORF cloning } \\
\hline OBP17-forward & CTATGGAAATATGAAATGTTC & \\
\hline OBP17-reverse & ATGAACGGAATGAAAGGTTTACTGA & \multirow{5}{*}{ Escherichia coli expression } \\
\hline OBP12-forward & CGGGATCCGTTGAAATACGTCGAGATGATC (BamHI) & \\
\hline OBP12-reverse & CCCAAGCTTTTAAAGCAAGAAGTAATGTTTTGGA (HindIII) & \\
\hline OBP17-forward & $\overline{\text { CCCAAGCTTCTATGGAAATATGAAATGTTC (HindIII) }}$ & \\
\hline OBP17-reverse & CGGGATCCAGTTTATCTGTTGAAGAGC (BamHI) & \\
\hline
\end{tabular}

Restriction endonucleases are shown in parentheses after primers, and restriction sites are underlined. 
The entire coding regions of $\operatorname{SmosOBP12}$ and $\operatorname{SmosOBP17}$ were finally PCR amplified with gene-specific primers (Table 1). For $S m o s O B P 17, \mathrm{PCR}$ reactions were carried out under the following conditions: $3 \mathrm{~min}$ at $95^{\circ} \mathrm{C} ; 30$ cycles of $40 \mathrm{~s}$ at $95{ }^{\circ} \mathrm{C}, 50 \mathrm{~s}$ at $55^{\circ} \mathrm{C}, 60 \mathrm{~s}$ at $72{ }^{\circ} \mathrm{C}$; and $72{ }^{\circ} \mathrm{C}$ for $10 \mathrm{~min}$. For SmosOBP12, a 35-cycle touchdown PCR was performed. The thermocycling program included denaturation at $95^{\circ} \mathrm{C}$ for $3 \mathrm{~min}, 10$ cycles of $40 \mathrm{~s}$ at $95^{\circ} \mathrm{C}, 50 \mathrm{~s}$ at $60{ }^{\circ} \mathrm{C}$, and $60 \mathrm{~s}$ at $72{ }^{\circ} \mathrm{C}$ with a $1{ }^{\circ} \mathrm{C}$ decrease of annealing temperature per cycle. The remaining 25 cycles consisted of $40 \mathrm{~s}$ at $95^{\circ} \mathrm{C}, 50 \mathrm{~s}$ at $55{ }^{\circ} \mathrm{C}, 60 \mathrm{~s}$ at $72{ }^{\circ} \mathrm{C}$; and a final extension of $72{ }^{\circ} \mathrm{C}$ for $10 \mathrm{~min}$. Finally, PCR products were cloned and confirmed by sequencing analysis as described above.

\subsection{Sequence and Phylogenetic Analyses}

The online software ORF Finder (http://www.ncbi.nlm.nih.gov/gorf/gorf.html) was used to determine protein sequences of SmosOBP12 and SmosOBP17 from their cDNAs. The molecular weight and theoretical isoelectric points of these putative proteins were calculated with the Expasy server program (http://web.expasy.org/compute_pi/). N-terminal signal peptides were predicted using SignalP 5.0 server (http://www.cbs.dtu.dk/services/signalP-5.0). Sequence alignment of these two SmosOBPs with OBPs from other insects were carried out with the DANMAN 6.0 software (Lynnon Corporation, Pointe-Claire, QC, Canada). A phylogenetic tree was built by MEGA 10.0.5 (Temple University, Philadelphia, PA, USA) software using the neighbor-joining algorithm with 1000 bootstrap replications based on 41 OBP amino acid sequences from dipteran insects.

\subsection{Prokaryotic Expression and Purification of SmosOBPs}

Coding regions of $\mathrm{SmosOBP12}$ and $\mathrm{SmosOBP17}$ without signal peptides were PCR amplified and cloned into the pMD-19T vector (TaKaRa, Dalian, China). The constructs were then restricted by BamHI and HindIII (designed into the cloning primers, Table 1) and inserted in-frame into the expression vector pET28a (+) (Novagen, Madison, WI, USA) digested by the same restriction endonucleases. Sequence-confirmed pET28a/SmosOBP12 and pET28a/SmosOBP17 constructs were transformed into E. coli strains BL21 and Rosetta, respectively (Tiangen, Beijing, China).

Single colonies containing the verified insert sequences were cultured in Luria-Bertani (LB) media (containing $100 \mu \mathrm{g} / \mathrm{mL}$ kanamycin) in a shaker set at $220 \mathrm{rpm}$ and $37^{\circ} \mathrm{C}$. The overnight culture was used to inoculate $500 \mathrm{~mL}$ fresh medium with kanamycin. Expression of recombinant SmosOBPs were induced by addition of isopropyl $\beta$-D-1-thiogalactoside (IPTG) to a final concentration of $0.5 \mathrm{mM}$ when the culture reached $\mathrm{OD}_{600}$ of $0.6-0.8$. After a $5 \mathrm{~h}$ induction, cells were harvested by centrifugation at $6000 \mathrm{~g}$ for $10 \mathrm{~min}$. Cell pellets were homogenized in Tris- $\mathrm{HCl}$ buffer $(20 \mathrm{mM}, \mathrm{pH} 7.4)$, lysed with $0.4 \mathrm{mg} / \mathrm{mL}$ lysozyme, sonicated on ice (10 s, 15 passes), and centrifuged (12,000 g for $30 \mathrm{~min})$. Recombinant SmosOBPs were examined by SDS-PAGE. Expressed proteins in inclusion bodies were denatured with $8 \mathrm{M}$ urea and renatured by extensive dialysis following the procedure of a previous study [48].

Solubilized SmosOBPs were purified using the Ni-NTA His·Bind Resin affinity column (7Sea Pharmatech Co., Shanghai, China) following the procedure described in Li et al. (2016) [46], examined on $15 \%$ SDS-PAGE, and further verified by Western blot analysis using the mouse anti-His tag monoclonal antibody (Sino Biological, Beijing, China). Protein concentrations were determined by the Bicinchoninic Acid (BCA) Protein Assay Kit (GeneStar, Beijing, China).

\subsection{Fluorescence Competitive Binding Assays}

To determine binding affinities of SmosOBP12 and SmosOBP17 to host plant volatile compounds, fluorescence competitive binding assays were conducted using 1-N-phenyl-naphthylamine (1-NPN) as the fluorescent probe. Twenty-eight volatile compounds from winter wheat (Table 2) were selected based on our previous research [49]. Both the probe and candidate ligands were dissolved in chromatographic-grade methanol to obtain $1 \mathrm{mM}$ stock solutions, whereas recombinant SmosOBPs were diluted in $20 \mathrm{mM}$ Tris- $\mathrm{HCl}$ ( $\mathrm{pH}$ 7.4) to $2 \mu \mathrm{M}$. Fluorescence intensity was detected on an F-4600 
fluorescence spectrophotometer (Hitachi, Tokyo, Japan) with a $1 \mathrm{~cm}$ light path quartz cuvette. Slits of both excitation and emissions were $10 \mathrm{~nm}$ in width. The probe was excited at $337 \mathrm{~nm}$, and emission spectra were recorded between 370 and $550 \mathrm{~nm}$.

Table 2. Binding affinities of two SmosOBPs to wheat volatile compounds in fluorescence binding assays.

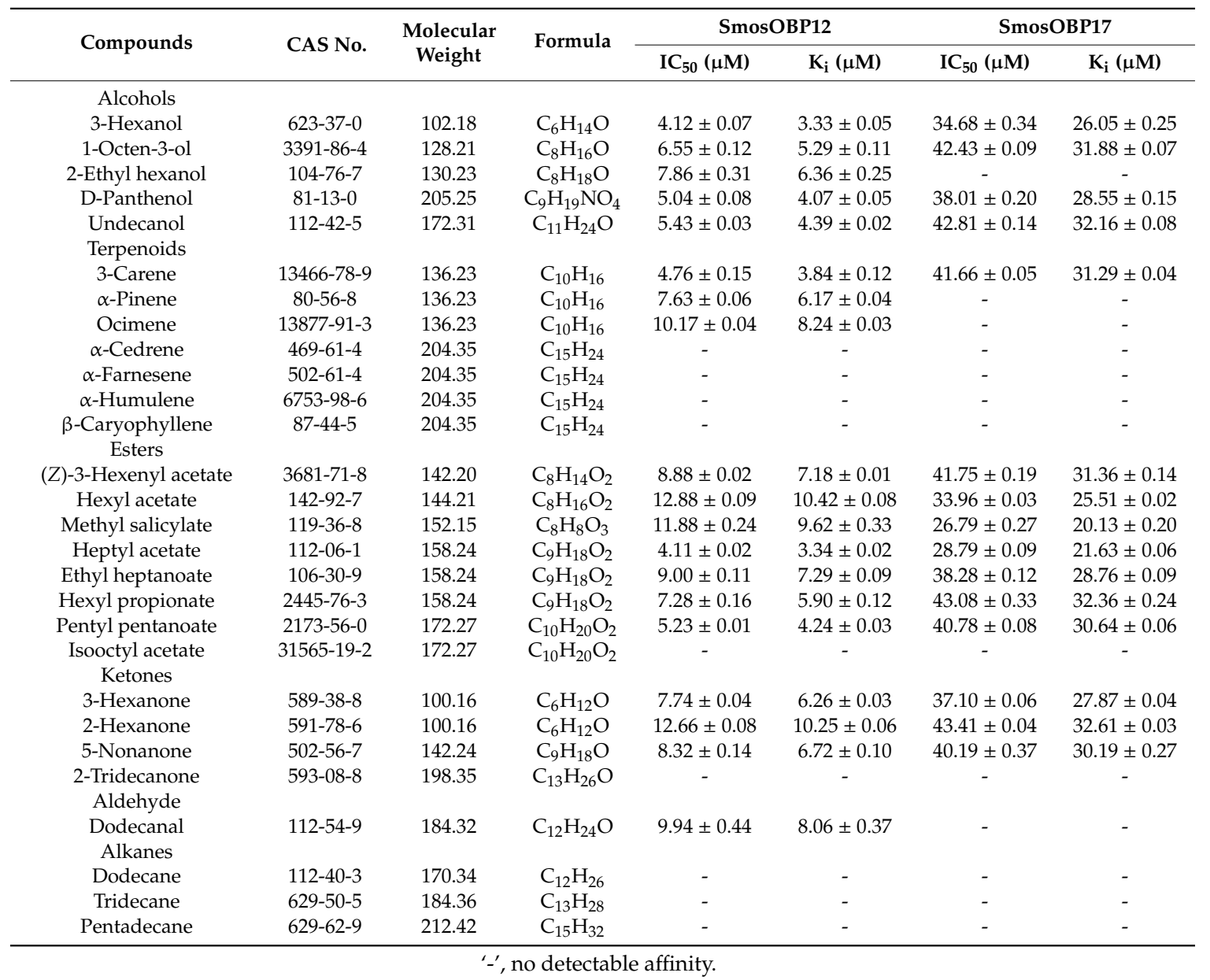

To obtain the dissociation constant $\left(\mathrm{K}_{\mathrm{d}}\right)$ of SmosOBPs and 1-NPN as a measurement of their binding affinity, $1 \mathrm{~mL}$ of a $2 \mu \mathrm{M}$ solution of each protein was titrated with aliquots of $1 \mathrm{mM} 1-\mathrm{NPN}$ to final concentrations of $0-24 \mu \mathrm{M}$, and the fluorescence intensities at the maximum fluorescence emission were recorded against the concentration of 1-NPN. Affinities of SmosOBPs to tested volatile ligands were measured by competition assays: to the $1 \mathrm{~mL}$ solution containing $2 \mu \mathrm{M}$ recombinant protein and $2 \mu \mathrm{M}$ 1-NPN, $1 \mathrm{mM}$ solution of each putative volatile ligand (in a $2 \mu \mathrm{L}$ aliquot) was added to final concentrations of 2-14 $\mu \mathrm{M}$ for SmosOBP12 and 2-40 $\mu \mathrm{M}$ for SmosOBP17, respectively. Maximal fluorescence intensities were plotted against ligand concentrations. Data were obtained from three independent measurements.

The $K_{d}$ value was calculated using GraphPad Prism 5 (GraphPad Software Inc., La Jolla, CA, USA) via nonlinear regression for a unique site of binding. The inhibition constant $\left(\mathrm{K}_{\mathrm{i}}\right)$ of each ligand competitor was calculated from the corresponding $\mathrm{IC}_{50}$ value (the concentration of competitor displacing $50 \%$ of initial fluorescence intensity) according to the equation: $\mathrm{K}_{\mathrm{i}}=\left[\mathrm{IC}_{50}\right] /\left(1+[1-\mathrm{NPN}] / \mathrm{K}_{1-\mathrm{NPN}}\right)$, where [1-NPN] is the free concentration of $1-\mathrm{NPN}$, and $\mathrm{K}_{1-\mathrm{NPN}}$ is the dissociation constant of the SmosOBPs/1-NPN complex [50]. We considered ligand binding affinity to SmosOBPs very strong $\left(\mathrm{K}_{\mathrm{i}} \leq 5 \mu \mathrm{M}\right)$, strong $\left(5 \mu \mathrm{M}<\mathrm{K}_{\mathrm{i}} \leq 15 \mu \mathrm{M}\right)$, medium $\left(15 \mu \mathrm{M}<\mathrm{K}_{\mathrm{i}} \leq 30 \mu \mathrm{M}\right)$, and weak $\left(\mathrm{K}_{\mathrm{i}}>30 \mu \mathrm{M}\right)$ in this study. 


\subsection{Y-Tube Olfactometer Bioassays}

Behavioral responses of $S$. mosellana females to the 28 volatile ligands were measured in a glass Y-tube olfactometer. The base and two arms of the Y-tube are $15 \mathrm{~cm}$ in length and $25 \mathrm{~mm}$ in internal diameter. The angle between arms is $60^{\circ}$. A $10 \mu \mathrm{L}$ aliquot of the test chemical in paraffin oil at a concentration of $20 \mu \mathrm{g} / \mu \mathrm{L}$ [45] was applied to a filter paper strip $(20 \times 20 \mathrm{~mm})$, which was allowed to evaporate for $20 \mathrm{~s}$ and then placed into one of the two odor bottles. The other odor bottle contained a filter paper strip treated with $10 \mu \mathrm{L}$ of paraffin oil as the control. Moist, activated-charcoal filtered air entered both odor bottles connected by Teflon tubing to their respective arms of the Y-tube. The airflow rate through the olfactometer was $100 \mathrm{~mL} / \mathrm{min}$, which was measured by a float rotor meter. A newly emerged female $S$. mosellana adult was introduced into the end of the base of the Y-tube, which was then immediately covered with a dark paper box. An office lamp $(20 \mathrm{~W})$ illuminated the joint of two arms to facilitate observation. The choice was made if the $S$. mosellana female walked or flew $5 \mathrm{~cm}$ past the $\mathrm{Y}$ junction within $5 \mathrm{~min}$ and remained there for at least $15 \mathrm{~s}$. Otherwise, it would be recorded as no-choice. Odor source was renewed for every five individuals. After testing for 10 individuals, the.Y-tube was thoroughly cleaned with 95\% ethanol and dried, and the treatment and control arms were switched to avoid the directional bias. After one odor source was tested, the Y-tube, odor bottles, and Teflon tubing were cleaned and dried before reuse. All experiments were conducted in a laboratory with a temperature of $25 \pm 1^{\circ} \mathrm{C}$ from 5:00 to 9:00 p.m. Sixty female adults were tested in each treatment group, and each individual was used only once.

The choice response of insects in each treatment group was analyzed by the chi-square test using SPSS 20.0 software (Chicago, IL, USA). Non-selecting insects were recorded but not included in the statistical analysis.

\section{Results}

\subsection{Characterization of SmosOBP cDNAs}

The full-length cDNAs of SmosOBP12 (accession No. MG585343) and SmosOBP17 (MG585345) were obtained by RACE-PCR and ordinary PCR using gene-specific primers. ORFs of SmosOBP12 and SmosOBP17 encoded for proteins of 145 and 143 amino acid residues (Figure S1), respectively. The predicted molecular weight and isoelectric point for SmosOBP12 were $14.97 \mathrm{kDa}$ and 5.38, and $14.08 \mathrm{kDa}$ and 5.14 for SmosOBP17. Sequence analysis indicated that both SmosOBPs possessed signal peptides of 18-22 amino acid residues at their $\mathrm{N}$-termini (Figure S1). Moreover, they had the typical signature of six cysteines in the pattern of $C_{1}-X_{26}-C_{2}-X_{3}-C_{3}-X_{40}-C_{4}-X_{8-10}-C_{5}-X_{8}-C_{6}$ (Figure 1 and Figure S1). Therefore, they belong to the classic OBP subfamily [51].

Amino acid sequence alignment of SmosOBPs with homologues from other dipterans indicated that SmosOBP12 shared the highest sequence identities (65.3\%) to Bradysia odoriphaga OBP28 (BodoOBP28) followed by BodoOBP1 (62.2\% identity); SmosOBP17 had the highest sequence identities (39.8\%) to Aedes aegypt OBP3 (AaegOBP3) and Drosophila guanche OBP19a (DguaOBP19a) (38.4\% identity). The'two SmosOBPs displayed a relatively lower homology (25.0\%) (Figure 1A). The phylogenetic analysis grouped the 41 OBPs from $S$. mosellana and other dipterans into two branches, and SmosOBP12 and SmosOBP17 fell into different branches. The closest homologues were BodoOBP28 for SmosOBP12, and AaegOBP3 for SmosOBP17 (Figure 1B). 
A

$$
\begin{aligned}
& \text { ASmosOBP12 } \\
& \text { ASmosOBP17 } \\
& \text { BodoOBP28 } \\
& \text { BodoOBP1 } \\
& \text { BodoOBP2 } \\
& \text { AfunOBP1 } \\
& \text { ZtauOBP2b } \\
& \text { BminOBP83a } \\
& \text { DPlaOBP5 } \\
& \text { DantOBP5 } \\
& \text { DguaOBP19a } \\
& \text { BdorOBP19a } \\
& \text { LsatOBP1 } \\
& \text { AaegOBP3 }
\end{aligned}
$$

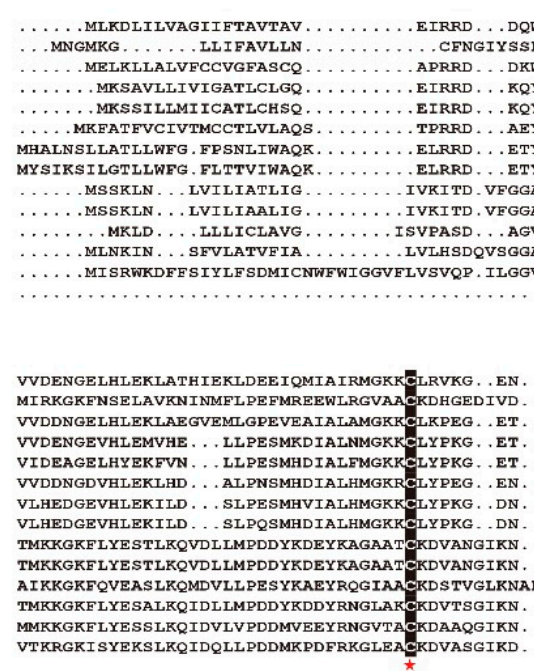

IRRD . . . DQWPPPEVVAIVQPMRIVCTREKT . GVTDEAIREFSDGE IHEDEALKC . GASDDLIDGINVGQFPRDQNLMCYINCLLTMMR 作 作 作 . ETYPPPELLLKALOPVHDSCVAKI . GVTEEAIKEF SDGDVHEDELLKCYMYCVEEETD TPPELIKALQPVHDSCVAKI . GVTEEAIKEF SDGDVHEDELLKCYMYCVFEETD TEEQMWAAGALMRDV CFPKF PKVSKELADGI RA GNLPDERDAKCYVNC ILEMMQ

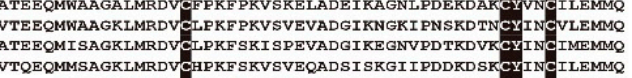

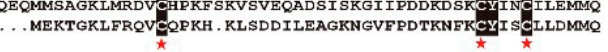
Identity (z)
$\begin{array}{cc}\text { SmosoBP12 } & \text { SmosoBP17 } \\ 100.00 & 25.00\end{array}$

\begin{tabular}{l} 
ASmosOBP12 \\
\hline ASmoBOBP17 \\
BodoOBP28 \\
BodoOBP1 \\
BodoOBP2 \\
AfunOBP1 \\
ZtauOBP2b \\
BminOBP83a \\
DplaOBP5 \\
DantOBP5 \\
DguaOBP19a \\
BdorOBP19a \\
LsatoBP1 \\
AaegOBP3
\end{tabular}

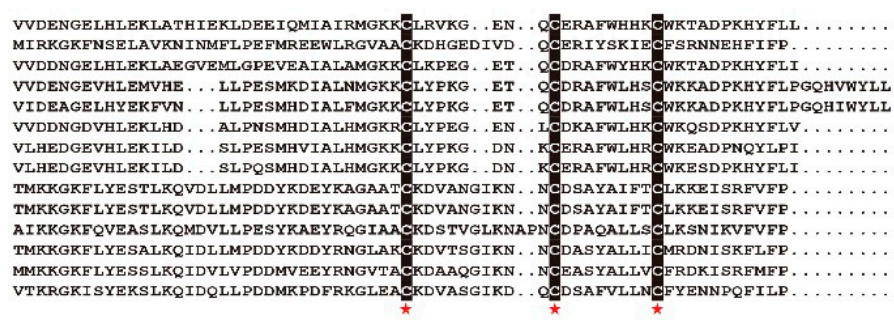
$100.00-145$ $\begin{array}{lll}65.32 & 21.55 & 145\end{array}$ $\begin{array}{ll}62.24 & 25.42\end{array}$ $\begin{array}{ll}60.14 & 25.42 \\ 58.87 & 21.55\end{array}$

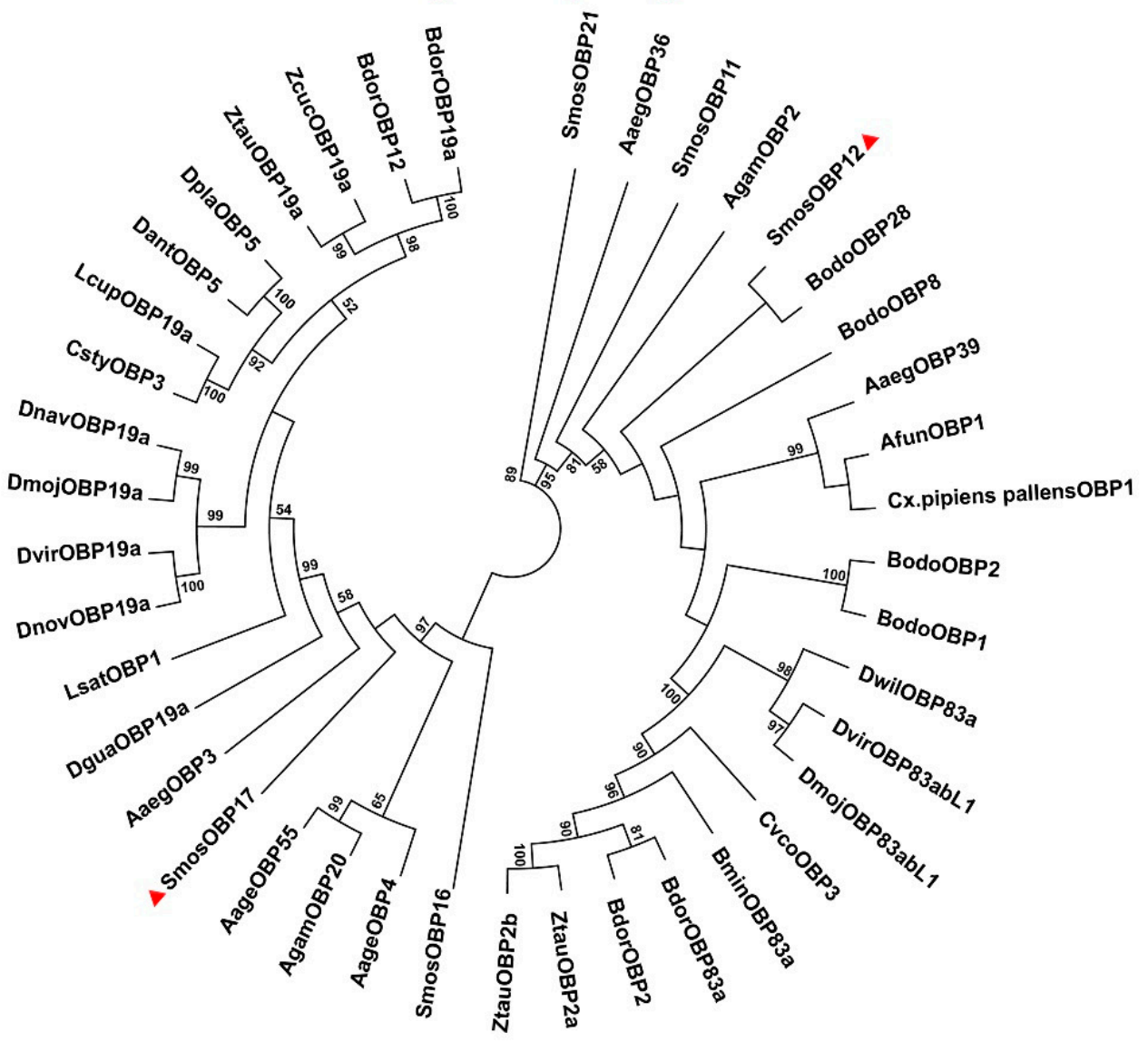

Figure 1. Multiple sequence alignment (A) and phylogenetic analysis (B) of Sitodiplosis mosellana odorant-binding proteins (SmosOBPs) and dipteran homologs. Six conserved cysteines are marked with red asterisks. SmosOBP12 and SmosOBP17 are indicated by red triangles. The phylogenetic tree was built using the neighbor-joining method with 1000 bootstrap replications and presented with a cutoff value of 50. Gene names and GenBank accession numbers of 41 OBPs are as follows: S. mosellana (SmosOBP12, MG585343; SmosOBP17, MG585345; SmosOBP11, MG585344; SmosOBP16, KF782364; SmosOBP21, KF782358); Bradysia odoriphaga (BodoOBP28, AWC08439.1; BodoOBP1, ANA52575.1; BodoOBP2, ANA52576.1; BodoOBP8, AWC08439.1); Anopheles funestus (AfunOBP1, ADQ01701.1); 
Zeugodacus tau (ZtauOBP2b, AKB92821.1; ZtauOBP19a, ALS40418.1; ZtauOBP2a, AKB92820.1); Bactrocera minax (BminOBP83a, AYN70647.1); Delia platura (DplaOBP5, BAS69445.1); Delia antiqua (DantOBP5, BAI82445.1); Drosophila Guanche (DguaOBP19a, SPP78474.1); Bactrocera dorsalis (BdorOBP19a, AKI28998.1; BdorOBP12, AKM45830.1; BdorOBP2, AGO28153.1; BdorOBP83a, XP_011212472.1); Liriomyza sativae (LsatOBP1, ALZ41694.1); Aedes aegypti (AaegOBP3, AAEL000051; AaegOBP4, AAEL000073; AaegOBP36, AAEL008011; AaegOBP39, AAEL009449; AaegOBP55, AAEL012377); Anopheles gambiae (AgamOBP2, AAO12083.1; AgamOBP20, AAO12087.1); Drosophila navojoa (DnavOBP19a, XP_017965215.1); Drosophila mojavensis (DmojOBP19a, XP_002011011.1; DmojOBP83abL1, XP_001999215.1); Drosophila virilis (DvirOBP19a, XP_002058161.1; DvirOBP83abL1, XP_002058580.1); Drosophila novamexicana (DnovOBP19a, XP_030568576.1); Zeugodacus cucurbitae (ZcucOBP19a, XP_011187213.1); Lucilia cuprina (LcupOBP19a, XP_023294703.1); Calliphora stygia (CstyOBP3, AID61296.1); Culex pipiens pallens (Cx.pipiens pallensOBP1, AMQ13063.1); Drosophila willistoni (DwilOBP83a, XP_002073644.2); Carpomya vesuviana (CvesOBP3, AMY98994.1).

\subsection{Expression and Purification of SmosOBPs}

Both SmosOBPs were successfully expressed in the prokaryotic expression system after IPTG induction but were present in inclusion bodies (Figure 2). Yields of the renatured proteins were $0.89 \mathrm{mg} / \mathrm{mL}$ for SmosOBP12 and $0.60 \mathrm{mg} / \mathrm{mL}$ for SmosOBP17. Specific bands of expected sizes corresponding to the purified SmosOBP12 and SmosOBP17 were detected on both SDS-PAGE and Western blot analysis (Figure 2).

SmosOBP12

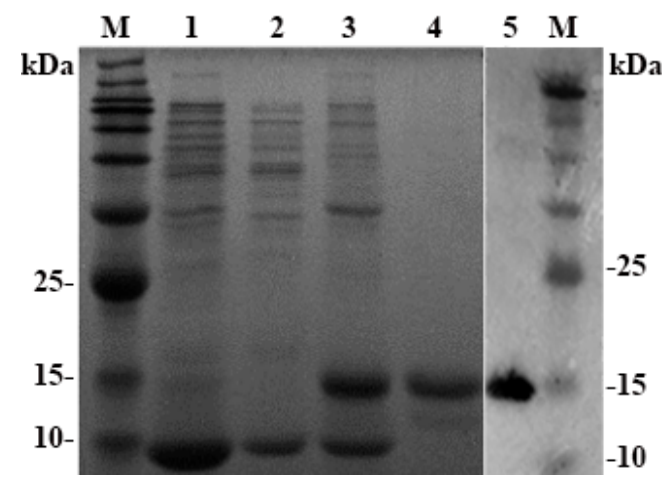

\section{SmosOBP17}

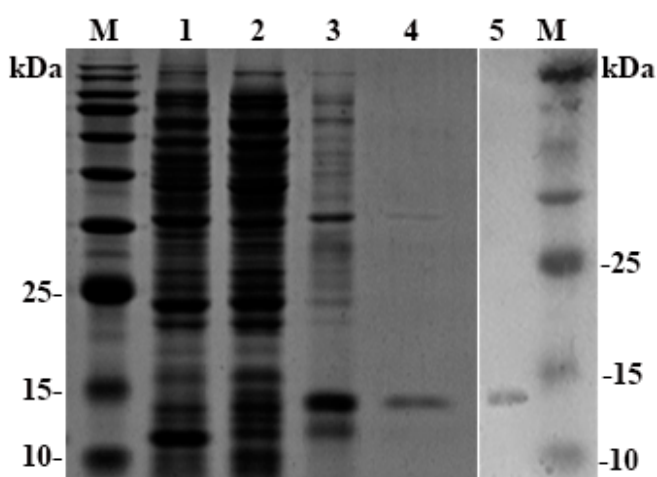

Figure 2. Bacterially expressed SmosOBP12 and SmosOBP17. SDS-PAGE of un-induced recombinant Escherichia coli harboring pET28a (+)/SmosOBPs (lane 1), supernatant (lane 2) and precipitate (lane 3) of IPTG-induced E. coli, and Ni-NTA affinity-purified SmosOBPs (lane 4). Western blot analysis of purified SmosOBPs (lane 5). M, molecular weight markers.

\subsection{Distinct Binding Affinities of SmosOBPs12 and 17 to Host Plant Volatiles}

To explore the function of the two SmosOBPs in perception of wheat plant volatiles, we first measured their binding affinities to the fluorescent probe 1-NPN. Based on the changes in the fluorescence intensity, dissociation constants $\left(\mathrm{K}_{\mathrm{d}}\right)$ with 1-NPN were 4.26 and $3.02 \mu \mathrm{M}$ for SmosOBP12 and $\mathrm{SmosOBP17}$, respectively (Figure 3A). 
A
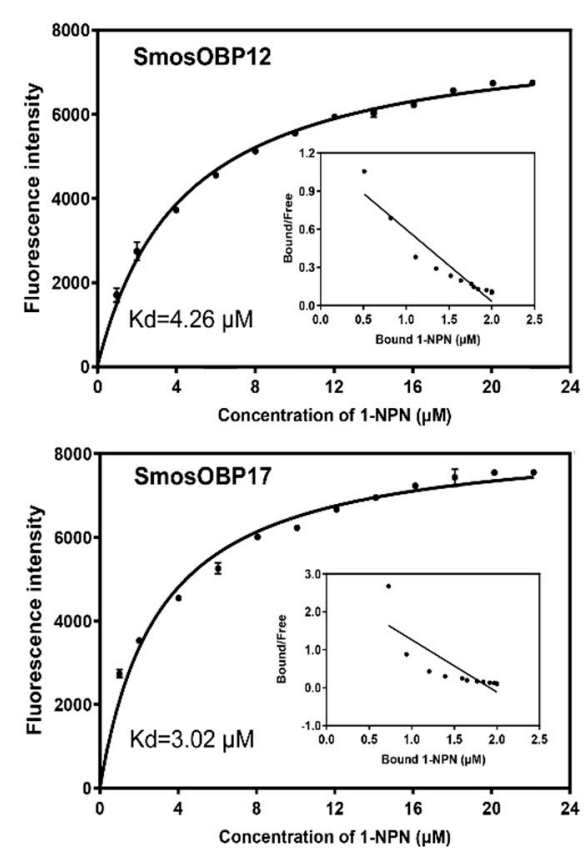

B
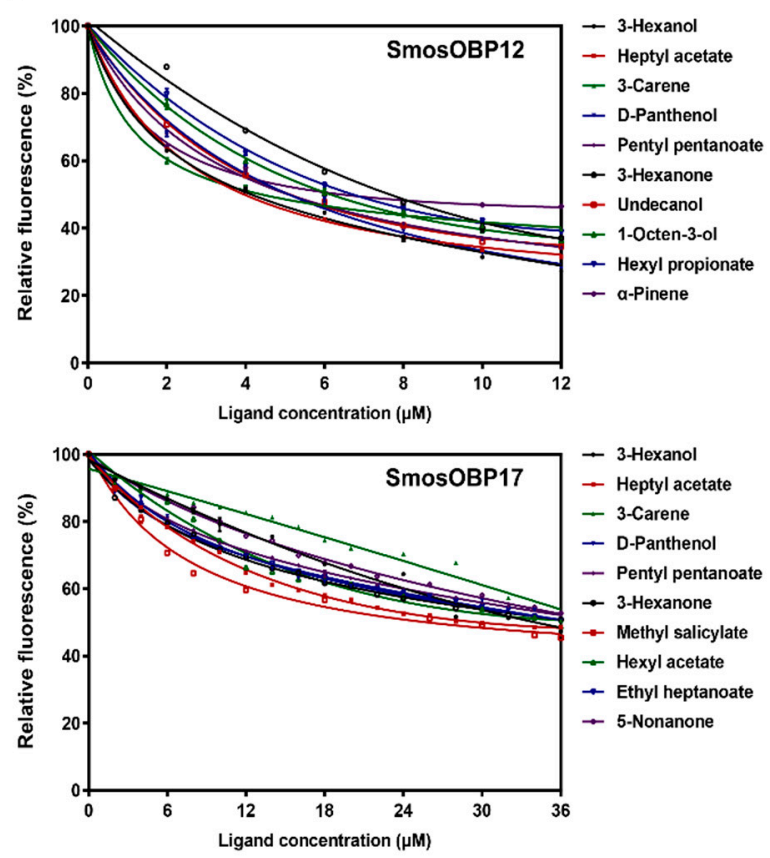

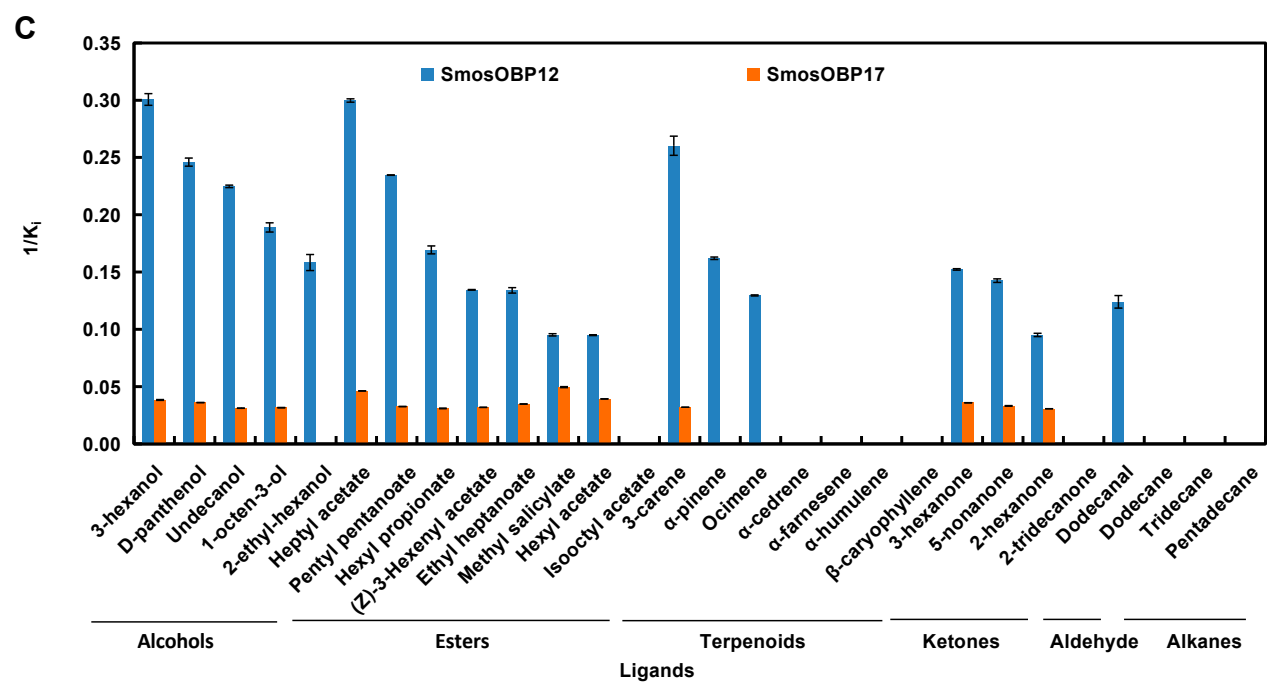

Figure 3. Ligand-binding assays of recombinant SmosOBP12 and SmosOBP17. (A) Binding curves and Scatchard plots of SmosOBP/1-NPN associations. (B) Fluorescence competitive binding curves of SmosOBPs to the 10 tightest bound ligands. (C) Affinities $\left(1 / \mathrm{K}_{\mathrm{i}}\right)$ of tested ligands to the two SmosOBPs. Data are means of three independent experiments. The error bars of some points may not be clearly seen because they are too small to be displayed.

Recombinant SmosOBP12 and SmosOBP17 exhibited distinct binding to tested compounds (Figure 3B,C). SmosOBP12 bound to 19 odorants, while SmosOBP17 bound to 15 odorants (Figure 3C, Table 2). For those commonly shared volatile substrates, SmosOBP12 showed stronger binding than SmosOBP17. Specifically, SmosOBP12 showed very strong $\left(\mathrm{K}_{\mathrm{i}}<5 \mu \mathrm{M}\right)$ or strong affinities $\left(K_{i}=10.25-10.42 \mu \mathrm{M}\right)$ to all five tested alcohols, three of the seven terpenoids (ocimene, $\alpha$-pinene, and 3-carene), seven of the eight esters (except isooctyl acetate), three of the four ketones (3-hexanone, 2-hexanone, and 5-nonanone), and dodecanal. In contrast, SmosOBP17 did not bind to 2-ethylhexanol, ocimene, $\alpha$-pinene, and dodecanal; and showed medium $\left(\mathrm{K}_{\mathrm{i}}=20.13-28.76 \mu \mathrm{M}\right)$ or weak affinities $\left(K_{i}=30.19-32.61 \mu \mathrm{M}\right)$ to the other four alcohols, seven esters, three ketones, and 3-carene. Interestingly, 
two SmosOBPs displayed obviously different binding preference for several compounds with the same molecular formula, such as $\mathrm{C}_{10} \mathrm{H}_{16}$ (i.e., 3-carene, $\alpha$-pinene and ocimene), $\mathrm{C}_{9} \mathrm{H}_{18} \mathrm{O}_{2}$ (i.e., heptyl acetate, ethyl heptanoate, and hexyl propionate), $\mathrm{C}_{10} \mathrm{H}_{20} \mathrm{O}_{2}$ (i.e., pentyl pentanoate and isooctyl acetate) and $\mathrm{C}_{6} \mathrm{H}_{12} \mathrm{O}$ (i.e., 2-hexanone and 3-hexanone). They had stronger affinities with 3-carene, heptyl acetate, pentyl pentanoate, and 3-hexanone compared to their isomers. Clearly, the best four ligands were 3-hexanol, heptyl acetate, 3-carene, and D-panthenol for SmosOBP12 with $\mathrm{K}_{\mathrm{i}}$ value ranging from 3.33 to $4.07 \mu \mathrm{M}$; and methyl salicylate, heptyl acetate, hexyl acetate, and 3-hexanol for SmosOBP17 with $\mathrm{K}_{\mathrm{i}}$ value ranging from 20.13 to $26.05 \mu \mathrm{M}$ (Figure 3B, Table 2). On the other hand, all three tested alkanes, four terpenoids with the same molecular formula of $\mathrm{C}_{15} \mathrm{H}_{24}$ (i.e., $\alpha$-cedrene, $\alpha$-farnesene, $\alpha$-humulene, and caryophyllene), isooctyl acetate, or 2-tridecanone did not show any affinity to either of the SmosOBPs.

\subsection{Behavior of S. mosellana in Y-Tube Olfactometer Assays}

Among the 28 volatiles tested, 11 could elicit obvious behavioral response of $S$. mosellana female adults. Adults showed a significant attraction to nine of them, including 1-octen-3-ol $\left(\chi^{2}=9.981\right.$, $p=0.002)$, methyl salicylate $\left(\chi^{2}=9.000, p=0.003\right)$, ethyl heptanoate $\left(\chi^{2}=8.647, p=0.003\right)$, heptyl acetate $\left(\chi^{2}=7.681, p=0.006\right),(Z)-3$-hexenylacetate $\left(\chi^{2}=8.321, p=0.004\right), \mathrm{D}$-panthenol $\left(\chi^{2}=7.367, p=0.007\right)$, hexyl acetate $\left(\chi^{2}=6.654 p=0.010\right)$, 3-carene $\left(\chi^{2}=5.333, p=0.021\right)$, and 3-hexanol $\left(\chi^{2}=4.412, p=0.036\right)$. In contrast, they also displayed a significant repulsion to $\alpha$-farnesene $\left(\chi^{2}=15.868, p=0.000\right)$ and ocimene $\left(\chi^{2}=8.321, p=0.004\right)$. The remaining 17 compounds were neither attractive nor repulsive to S. mosellana (Figure 4$)$.

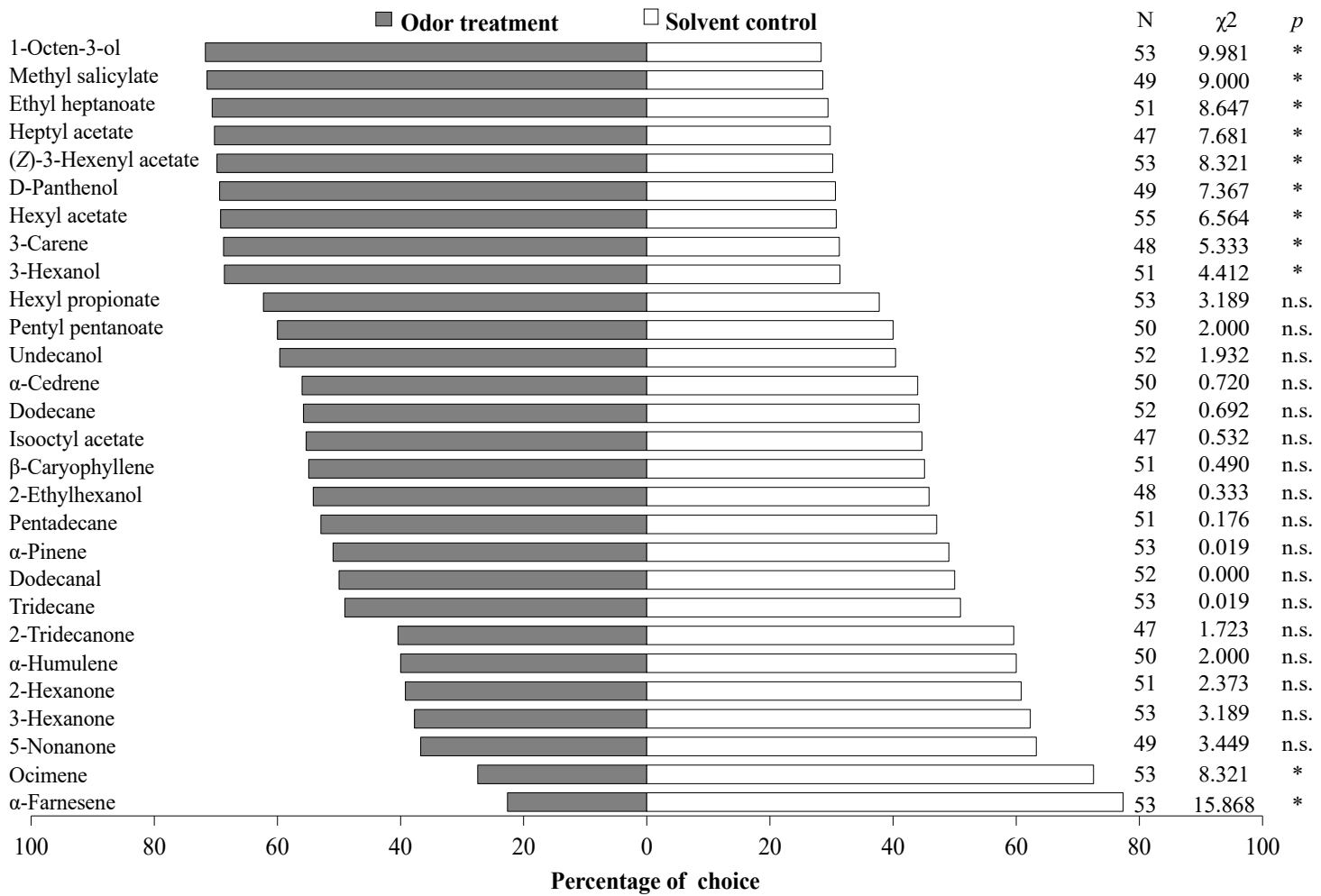

Figure 4. Responses of female Sitodiplosis mosellana adults to synthetic odors derived from wheat volatiles. All tested compounds subjected to Y-tube olfactometer assays were diluted with liquid paraffin to a final concentration of $20 \mu \mathrm{g} / \mu \mathrm{L}$ and liquid paraffin was used as the solvent control. N marks the number of individuals that made a choice out of 60 tested insects, and the insects that did not make a choice are excluded from the statistical analysis. Asterisk denotes significant difference $(p<0.05)$, and n.s. indicates no significant difference by chi-square tests. 


\section{Discussion}

Annotation of insect genomes and antennal transcriptomes has resulted in identification of numerous $O B P$ genes. It is generally believed that those abundant in adult antennae are essential for olfaction, enabling insects to detect volatile compounds for mating, foraging, and locating suitable oviposition sites $[28,46,52]$. Of the two $S$. mosellana OBP genes cloned in this study, SmosOBP12 is highly and specifically expressed in antennae of female adults, and SmosOBP17 is mainly expressed in antennae of both sexes [44], implying potential roles in the detection of host plant volatiles. Limited sequence identity between the two proteins (25\%) (Figure 1) suggests their functional divergence.

S. mosellana thrives mainly on wheat, and depends heavily on volatile cues of wheat ears before anthesis to select wheat varieties for oviposition [38,49]. To elucidate differential roles played by SmosOBPs in perceiving host odors, volatiles from wheat ears were used as putative ligands in fluorescence competitive binding assays in the present study. Similar to many other insect OBPs such as OBPs 3 and 8 in Agrilus mali [19], OBPs 2 and 6 in Chrysoperla sinica [31], OBPs 1 and 2 in Chilo suppressalis [53], and OBP1 in Adelphocoris lineolatus [16], SmosOBPs 12 and 17 could selectively recognize functional groups of host odorants. SmosOBPs 12 and 17 failed to bind any of the alkanes tested, but could effectively bind to most alcohols, esters, and ketones, as well as terpenoid compounds, and SmosOBP12 also bound dodecanal (Table 2). Furthermore, we found that the carbon chain length and steric configuration of odorant molecules also affected their interaction with SmosOBPs. For example, the two SmosOBPs could bind ketones and terpenoids that have short carbon chains (C6-C10), but not those with long chains (C13-C15) (Table 2). They showed greater affinities for 3-carene, ethyl heptanoate, and 3-hexanone than their isomers $\alpha$-pinene, isooctyl acetate, and 2-hexanone, respectively. Consistently, Spodoptera litura GOBP1 and Loxostege sticticalis GOBP2 prefer shorter-chain esters or aldehydes to longer-chain forms [27,30]. Likewise, G. molesta OBP11 and A. lineolatus OBP1 can distinguish isomers of ketones or terpenoids [16,46].

Notably, SmosOBP12 displayed a broader ligand-binding spectrum with higher affinity to alcohols, esters, ketones, terpenoids, and aldehydes $\left(\mathrm{K}_{\mathrm{i}}<10.5 \mu \mathrm{M}\right)$ compared to SmosOBP17 $\left(\mathrm{K}_{\mathrm{i}}>20.1 \mu \mathrm{M}\right)$ as well as to SmosOBPs 11, 16, and 21, three antenna-specific OBPs that we previously reported [45], indicating that SmosOBP12 may play more crucial roles than other SmosOBPs in perceiving host plant volatiles. Similar findings were also reported before [30,52,54]. For instance, GOBP2 of Agrotis ipsilon binds a wider range of plant odorants with a greater affinity than AipsGOBP1 [28]. OBP4 from $M$. mediator has a broader binding spectrum as well as stronger affinity than MmedOBPs 5 and 7 with the tested host volatiles [33].

We have shown earlier that 3-hexanol, 1-octen-3-ol, D-panthenol, (Z)-3-hexenylacetate, hexyl acetate, methyl salicylate, heptyl acetate, and ethyl heptanoate elicit strong electrophysiological responses on the female antennae of S. mosellana (Cheng et al., 2020). In our behavioral tests here, these compounds significantly attracted S. mosellana females (Figure 4). It is thus conceivable that some of these volatiles could be used for development of $S$. mosellana attractants for monitoring and management of this pest. SmosOBP12 most likely facilitates transportation of these compounds to olfactory receptors due to its particularly strong affinity to the volatiles $\left(\mathrm{K}_{\mathrm{i}}<10.5 \mu \mathrm{M}\right)$ (Table 2). In contrast, ocimene exerted a strong repelling effect on female S. mosellana (Figure 4), which may explain its high abundance in less-preferred wheat varieties Shanmai 139 and Jinmai 47 for S. mosellana oviposition [49]. SmosOBPs 11, 16, 17, and 21 did not bind this compound, but SmosOBP12 exhibited high affinity to it $\left(\mathrm{K}_{\mathrm{i}}=8.2 \mu \mathrm{M}\right)$, implying that ocimene is more likely to function in host selection through specific interaction with SmosOBP12. Notably, $\alpha$-farnesene also repelled S. mosellana but showed no affinity to any of the five SmosOBPs identified up to date [45]. Presumably, other OBPs in S. mosellana are responsible for binding and transportation of this key odorant [44], and further study is necessary to fully elucidate molecular mechanisms underlying host selection in S. mosellana. 


\section{Conclusions}

In conclusion, our in vitro binding and behavioral assays strongly suggested that both SmosOBP12 and SmosOBP17 could selectively detect and recognize host wheat volatiles which impact host selection behavior of S. mosellana. Combined with our earlier study on SmosOBPs11, 16, and 21, we concluded that SmosOBP12 may play the most prominent role in this process. Although application of RNA interference to confirm biological functions of SmosOBPs is the apparent follow-up study, it is not yet technically feasible at the present time for this particular species. Targeted technical development will no doubt be crucial in facilitating in vivo functional dissection of SmosOBPs and for OBP-based behavioral interference for monitoring and control of this key pest.

Supplementary Materials: The following are available online at http://www.mdpi.com/2075-4450/11/12/891/s1, Figure S1: Nucleotide and deduced amino acid sequences of SmosOBP12 and SmosOBP17 in Sitodiplosis mosellana. Start and stop codons are boxed. Predicated signal peptides are underlined. The six conserved cysteines are circled.

Author Contributions: Conceptualization, W.C. and K.Z.-S.; methodology, Y.Z. and W.C.; investigation, Y.Z.; formal analysis, Y.Z., J.Y., W.L., and W.C.; writing-original draft preparation, W.C.; writing-review and editing, W.C. and K.Z.-S. All authors have read and agreed to the published version of the manuscript.

Funding: This work was supported by the National Key Research and Development Program of China (2018YFD0200402), the Key Research and Development Program of Shaanxi province, China (2020NY-059), and the National Natural Science Foundation of China (31371933).

Conflicts of Interest: The authors declare no conflict of interest.

\section{References}

1. Fürstenau, B.; Rosell, G.; Guerrero, A.; Quero, C. Electrophysiological and behavioral responses of the black-banded oak borer, Coroebus florentinus, to conspecific and host-plant volatiles. J. Chem. Ecol. 2012, 38, 378-388. [CrossRef] [PubMed]

2. Diaz-Santiz, E.; Rojas, J.C.; Cruz-Lopez', L.; Hernandez', E.; Malo, E.A. Olfactory response of Anastrepha striata (Diptera:Tephritidae) to guava and sweet orange volatiles. Insect Sci. 2016, 23, 720-727. [CrossRef]

3. Karageorgi, M.; Bräcker, L.B.; Lebreton, S.; Minervino, C.; Cavey, M.; Siju, K.P.; Grunwald Kadow, I.C.; Gompel, N.; Prud'homme, B. Evolution of multiple sensory systems drives novel egg-laying behavior in the fruit pest Drosophila suzukii. Curr. Biol. 2017, 27, 847-853. [CrossRef] [PubMed]

4. Cloonan, K.R.; Abraham, J.; Angeli, S.; Syed, Z.; Rodriguez-Saona, C. Advances in the chemical ecology of the spotted wing drosophila (Drosophila suzukii) and its applications. J. Chem. Ecol. 2018, 44, 922-939. [CrossRef] [PubMed]

5. Leal, W.S. Odorant reception in insects: Roles of receptors, binding proteins, and degrading enzymes. Ann. Rev. Entomol. 2013, 58, 373-391. [CrossRef] [PubMed]

6. Zhu, J.; Ban, L.; Song, L.M.; Liu, Y.; Pelosi, P.; Wang, G. General odorant-binding proteins and sex pheromone guide larvae of Plutella xylostella to better food. Insect Biochem. Mol. Biol. 2016, 72, 10-19. [CrossRef]

7. Zhang, R.; Wang, B.; Grossi, G.; Falabella, P.; Liu, Y.; Yan, S.; Lu, J.; Xi, J.; Wang, G. Molecular basis of alarm pheromone detection in aphids. Curr. Biol. 2017, 27, 55-61. [CrossRef]

8. Wang, Y.L.; Jin, Y.C.; Chen, Q.; Wen, M.; Zhao, H.B.; Duan, H.X.; Ren, B.Z. Selectivity and ligand-based molecular modeling of an odorant binding protein from the leaf beetle Ambrostoma quadriimpressum (Coleoptera: Chrysomelidae) in relation to habitat-related volatiles. Sci. Rep. 2017, 7, 15374. [CrossRef]

9. Yin, J.; Wang, C.Q.; Fang, C.Q.; Zhang, S.; Cao, Y.Z.; Li, K.B.; Leal, W.S. Functional characterization of odorant-binding proteins from the scarab beetle Holotrichia oblita based on semiochemical-induced expression alteration and gene silencing. Insect Biochem. Mol. Biol. 2019, 104, 11-19. [CrossRef]

10. Zhou, J.J.; Field, L.M.; He, X.L. Insect odorant-binding proteins: Do they offer an alternative pest control strategy? Outlooks Pest Manag. 2010, 21, 31-34. [CrossRef]

11. Pelosi, P.; Mastrogiacomo, R.; Iovinella, I.; Tuccori, E.; Persaud, K.C. Structure and biotechnological applications of odorant-binding proteins. Appl. Microbiol. Biotechnol. 2014, 98, 61-70. [CrossRef] [PubMed] 
12. Li, Y.W.; Zhou, P.; Zhang, J.H.; Yang, D.; Li, Z.H.; Zhang, X.L.; Zhu, S.F.; Yu, Y.X.; Chen, N.Z. Identification of odorant binding proteins in Carpomya vesuviana and their binding affinity to the male-borne semiochemicals and host plant volatiles. J. Insect Physiol. 2017, 100, 100-107. [CrossRef] [PubMed]

13. Vogt, R.G.; Riddiford, L.M. Pheromone binding and inactivat ion by moth antennae. Nature 1981, 293,'161-163. [CrossRef] [PubMed]

14. Tuccini, A.; Maida, R.; Rovero, P.; Mazza, M.; Pelosi, P. Putative odorant-binding protein in antennae and legs of Carausius morosus (Insecta, Phasmatodea). Insect Biochem. Mol. Biol. 1996, 26, 19-24. [CrossRef]

15. Calvello, M.; Guerra, N.; Brandazza, A.; Ambrosio, C.D.; Scaloni, A.; Dani, F.R.; Turillazzi, S.; Pelosi, P. Soluble proteins of chemical communication in the social wasp Polistes dominulus. Cell. Mol. Life Sci. 2003, 60, 1933-1943. [CrossRef]

16. Gu, S.H.; Wang, W.X.; Wang, G.R.; Zhang, X.Y.; Guo, Y.Y.; Zhang, Z.D.; Zhou, J.J.; Zhang, Y.J. Functional characterization and immunolocalization of odorant binding protein 1 in the lucerne plant bug, Adelphocoris lineolatus (Goeze). Arch. Insect Biochem. Physiol. 2011, 77, 81-98. [CrossRef]

17. Zheng, J.G.; Li, J.R.; Han, L.; Wang, Y.; Wu, W.; Qi, X.X.; Tao, Y.; Zhang, L.; Zhang, Z.D.; Chen, Z.Z. Crystal structure of the Locusta migratoria odorant binding protein. Biochem. Biophys. Res. Commun. 2015, 456, 737-742. [CrossRef]

18. Niu, D.J.; Liu, Y.; Dong, X.T.; Dong, S.L. Transcriptome based identification and tissue expression profiles of chemosensory genes in Blattella germanica (Blattaria: Blattidae). Comp. Biochem. Physiol. Part D Genom. Proteom. 2016, 18, 30-43. [CrossRef]

19. Cui, X.N.; Liu, D.G.; Sun, K.K.; He, Y.; Shi, X.Q. Expression profiles and functional characterization of two odorant-binding proteins from the apple buprestid beetle Agrilus mali (Coleoptera: Buprestidae). J. Econ. Entomol. 2018, 11, 1420-1432. [CrossRef]

20. Tang, B.W.; Tai, S.L.; Dai, W.; Zhang, C.N. Expression and functional analysis of two dorant- binding proteins from Bradysia odoriphaga (Diptera: Sciaridae). J. Agric. Food Chem. 2019, 67, 3565-3574. [CrossRef]

21. Hekmat-Scafe, D.S.; Scafe, C.R.; McKinney, A.J.; Tanouye, M.A. Genome-wide analysis of the odorantbinding protein gene family in Drosophila melanogaster. Genome Res. 2002, 12, 1357-1369. [CrossRef] [PubMed]

22. Leal, W.S. Pheromone reception. Top. Curr. Chem. 2005, 240, 1-36.

23. Sun, M.J.; Liu, Y.; Wang, G.R. Expression patterns and binding properties of three pheromone binding proteins in the diamondback both, Plutella xyllostella. J. Insect Physiol. 2013, 59, 46-55. [CrossRef] [PubMed]

24. Song, Y.Q.; Dong, J.F.; Qiao, H.L.; Wu, J.X. Molecular characterization, expression patterns and binding properties of two pheromone-binding proteins from the oriental fruit moth, Grapholita molesta (Busck). J. Integr. Agric. 2014, 13, 2709-2720. [CrossRef]

25. Zhu, G.H.; Zheng, M.Y.; Sun, J.B.; Ali Khuhro, S.; Yan, Q.; Huang, Y.P.; Syed, Z.; Dong, S.L. CRISPR/Cas9 mediated gene knockout reveals a more important role of PBP1 than PBP2 in the perception of female sex pheromone components in Spodoptera litura. Insect Biochem. Mol. Biol. 2019, 115, 103244. [CrossRef]

26. Gong, Z.J.; Zhou, W.W.; Yu, H.Z.; Mao, C.G.; Zhang, C.X.; Cheng, J.; Zhu, Z.R. Cloning, expression and functional analysis of a general odorant-binding protein 2 gene of the rice striped stem borer, Chilo suppressalis (Walker) (Lepidoptera: Pyralidae). Insect Mol. Biol. 2009, 18, 405-417. [CrossRef]

27. Yin, J.; Feng, H.L.; Sun, H.Y.; Xi, J.H.; Cao, Y.Z.; Li, K.B. Functional analysis of general odorant binding protein 2 from the meadow moth, Loxostege sticticalis L. (Lepidoptera: Pyralidae). PLoS ONE 2012, 7, e33589. [CrossRef]

28. Huang, G.Z.; Liu, J.T.; Zhou, J.J.; Wang, Q.; Dong, J.Z.; Zhang, Y.J.; Li, X.C.; Li, J.; Gu, S.H. Expressional and functional comparisons of two general odorant binding proteins in Agrotis ipsilon. Insect Biochem. Mol. Biol. 2018, 98, 34-47. [CrossRef]

29. Li, K.M.; Wang, S.N.; Zhang, K.; Ren, L.Y.; Ali, A.; Zhang, Y.J.; Zhou, J.J.; Guo, Y. Y Odorant binding characteristics of three recombinant odorant binding proteins in Microplitis mediator (Hymenoptera: Braconidae). J. Chem. Ecol. 2014, 40, 541-548. [CrossRef]

30. Liu, N.Y.; Yang, K.; Liu, Y.; Xu, W.; Anderson, A.; Dong, S.L. Two general-odorant binding proteins in Spodoptera litura are differentially tuned to sex pheromones and plant odorants. Comp. Biochem. Physiol. Part A Mol. Integr. Physiol. 2015, 180, 23-31. [CrossRef] 
31. Li, Z.Q.; Zhang, S.; Cai, X.M.; Luo, J.Y.; Dong, S.L.; Cui, J.J.; Chen, Z.M. Distinct binding affinities of odorant-binding proteins from the natural predator Chrysoperla sinica suggest different strategies to hunt prey. J. Insect Physiol. 2018, 111, 25-31. [CrossRef] [PubMed]

32. Chen, X.L.; Su, L.; Li, B.L.; Li, G.W.; Wu, J.X. Molecular and functional characterization of three odorant binding proteins from the oriental fruit moth Grapholita molesta (Busck) (Lepidoptera: Tortricide). Arch. Insect Biochem. Physiol. 2018, 98, e21456. [CrossRef] [PubMed]

33. Zhang, S.; Chen, L.Z.; Gu, S.H.; Cui, J.J.; Gao, X.W.; Zhang, Y.J.; Guo, Y.Y. Binding characterization of recombinant odorant-binding proteins from the parasitic wasp, Microplitis mediator (Hymenoptera: Braconidae). J. Chem. Ecol. 2011, 37, 189-194. [CrossRef] [PubMed]

34. Chavalle, S.; Censier, F.; Gomeza, G.S.M.; De Profta, M. Protection of winter wheat against orange wheat blossom midge, Sitodiplosis mosellana (Géhin) (Diptera: Cecidomyiidae): Efficacy of insecticides and cultivar resistance insecticides and cultivar resistance. Pest Manag. Sci. 2015, 71, 783-790. [CrossRef] [PubMed]

35. Miao, J.; Huang, J.R.; Wu, Y.Q.; Gong, Z.J.; Li, H.L.; Zhang, G.Y.; Duan, Y.; Li, T.; Jiang, Y.L. Climate factors associated with the population dynamics of Sitodiplosis mosellana (Diptera: Cecidomyiidae) in central china. Sci. Rep. 2019, 9, 12361. [CrossRef] [PubMed]

36. Ding, H.; Lamb, R.J. Oviposition and larval establishment of Sitodiplosis mosellana (Diptera: Cecidomyiidae) on wheat (Gramineae) at different growth stages. Can. Entomol. 1999, 131, 475-481. [CrossRef]

37. Lamb, R.J.; Sridhar, P.; Smith, M.A.H.; Wise, I.L. Oviposition preference and offspring performance of a wheat midge Sitodiplosis mosellana (Géhin) (Diptera: Cecidomyiidae) on defended and less defended wheat plants. Environ. Entomol. 2003, 32, 414-420. [CrossRef]

38. Gharalari, A.H.; Smith, M.A.H.; Fox, S.L.; Lamb, R.J. Volatile compounds from non-preferred wheat spikes reduce oviposition by Sitodiplosis mosellana. Can. Entomol. 2011, 143, 388-391. [CrossRef]

39. Wang, Y.; Li, D.; Liu, Y.; Li, X.J.; Cheng, W.N.; Zhu-Salzman, K.Y. Morphology, ultrastructure and possible functions of antennal sensilla of Sitodiplosis mosellana Géhin (Diptera: Cecidomyiidae). J. Insect Sci. 2016, 16, 1-12. [CrossRef]

40. Jacquemin, G.; Chavalle, S.; De Proft, M. Forecasting the emergence of the adult orange wheat blossom midge, Sitodiplosis mosellana (Géhin) (Diptera: Cecidomyiidae) in Belgium. Crop Prot. 2014, 58, 6-13. [CrossRef]

41. Wang, Y.; Long, Z.R.; Feng, A.R.; Cheng, W.N. Effects of initial population number, wheat varieties and precipitation on infestation of Sitodiplosis mosellana (Diptera: Cecidomyiidae). Acta Agric. Boreali-Occident. Sin. 2015, 24, 165-171.

42. Smith, M.A.H.; Wise, I.L.; Lamb, R.J. Sex ratios of Sitodiplosis mosellana (Diptera: Cecidomyiidae): Implications for pest management in wheat (Poaceae). Bull. Entomol. Res. 2004, 94, 569-575. [CrossRef] [PubMed]

43. Hao, Y.N.; Miao, J.; Wu, Y.Q.; Gong, Z.J.; Jiang, Y.L.; Duan, Y.; Li, T.; Cheng, W.N.; Wu, J.X. Flight Performance of the Orange Wheat Blossom Midge (Diptera: Cecidomyiidae). J. Econ. Entomol. 2013, 106, 2043-2047. [CrossRef] [PubMed]

44. Gong, Z.J.; Miao, J.; Duan, Y.; Jiang, Y.L.; Li, T.; Wu, Y.Q. Identification and expression profile analysis of putative odorant-binding proteins in Sitodiplosis mosellana (Gehin) (Diptera: Cecidomyiidae). Biochem. Biophys. Res. Commun. 2014, 444, 164-170. [CrossRef] [PubMed]

45. Cheng, W.N.; Zhang, Y.D.; Liu, W.; Li, G.W.; Zhu-Salzman, K.Y. Molecular and functional characterization of three odorant-binding proteins from the wheat blossom midge, Sitodiplosis mosellana. Insect Sci. 2020, 27, 721-734. [CrossRef] [PubMed]

46. Li, G.W.; Zhang, Y.; Li, Y.P.; Wu, J.X.; Xu, X.L. Cloning, expression, and functional analysis of three odorant binding proteins of the oriental fruit moth, Grapholita molesta (Busck) (Lepidoptera: Tortricidae). Arch. Insect Biochem. Physiol. 2016, 91, 67-87. [CrossRef]

47. Cheng, W.N.; Long, Z.R.; Zhang, Y.D.; Liang, T.T.; Zhu-Salzman, K.Y. Effects of temperature, soil moisture and photoperiod on diapause termination and post-diapause development of the wheat blossom midge, Sitodiplosis mosellana (Géhin) (Diptera: Cecidomyiidae). J. Insect Physiol. 2017, 103, 73-85. [CrossRef]

48. Zhang, T.T.; Mei, X.D.; Feng, J.N.; Berg, B.G.; Zhang, Y.J.; Guo, Y.Y. Characterization of three pheromone-binding proteins (PBPs) of Helicoverpa armigera (Hubner) and their binding properties. J. Insect Physiol. 2012, 58, 941-948. [CrossRef] 
49. Han, X.Q. Host Selectivity of Sitodiplosis mosellana (Gehin) (Diptera: Decidomyiidae) Based on the Wheat Spike Volatiles. Master's Thesis, Northwest A \& F University, Yangling, China, 2017.

50. Campanacci, V.; Krieger, J.; Bette, S.; Sturgis, J.N.; Lartigue, A.; Cambillau, C.; Breer, H.; Tegoni, M. Revisiting the specificity of Mamestra brassicae and Antheraea polyphemus pheromone-binding proteins with a fluorescence binding assay. J. Biol. Chem. 2001, 276, 20078-20084. [CrossRef]

51. Zhou, J.J. Odorant-binding proteins in insects. Vitam. Horm. 2010, 83, 241-272.

52. Sun, L.; Wang, Q.; Yang, S.; Wang, Q.; Zhang, Z.; Khashaveh, A.; Zhang, Y.J.; Guo, Y.Y. Functional analysis of female-biased odorant binding protein 6 for volatile and nonvolatile host compounds in Adelphocoris lineolatus (Goeze). Insect Mol. Biol. 2017, 26, 601-615. [CrossRef] [PubMed]

53. Khuhro, S.A.; Liao, H.; Dong, X.T.; Yu, Q.; Yan, Q.; Dong, S.L. Two general odorant binding proteins display high bindings to both host plant volatiles and sex pheromones in a pyralid moth Chilo suppressalis (Lepidoptera: Pyralidae). J. Asia Pac. Entomol. 2017, 20, 521-528. [CrossRef]

54. Zhou, J.; Zhang, N.; Wang, P.; Zhang, S.C.; Li, D.Q.; Liu, K.Y.; Wang, G.X.; Wang, X.P.; Ai, H. Identification of host-plant volatiles and characterization of two novel general odorant-binding proteins from the legume pod borer, Maruca vitrata Fabricius (Lepidoptera: Crambidae). PLoS ONE 2015, 10, e0141208. [CrossRef] [PubMed]

Publisher's Note: MDPI stays neutral with regard to jurisdictional claims in published maps and institutional affiliations.

(C) 2020 by the authors. Licensee MDPI, Basel, Switzerland. This article is an open access article distributed under the terms and conditions of the Creative Commons Attribution (CC BY) license (http://creativecommons.org/licenses/by/4.0/). 